\title{
MOORING LINES RELIABILITY ANALYSIS CASE STUDY: FSO ABHERKA
}

\author{
Garry Raditya Putra I Daniel Mohammad Rosyid* I Rudi Walujo Prastianto
}

\footnotetext{
${ }^{1}$ Dept. of Ocean Engineering, Institut Teknologi Sepuluh Nopember, Surabaya, Indonesia
}

\section{Correspondence}

*Daniel Mohammad Rosyid, Dept of Ocean Engineering, Institut Teknologi Sepuluh Nopember, Surabaya, Indonesia. Email: dmrosyid@gmail.com

\section{Present Address}

Gedung Teknik Kelautan, J1. Teknik Kimia, Kampus ITS, Surabaya 60111, Indonesia

\begin{abstract}
Floating Storage and Offloading (FSO) demands good designs. One of the design is FSO's mooring lines. The mooring lines of the FSO would face various environmental conditions, so that they are required to have good reliability. FSO Abherka, installed in the Madura stratit, has dimensions of LOA 242.90 m, LPP $232 \mathrm{~m}$, Breadth $41.6 \mathrm{~m}$, Height $19.7 \mathrm{~m}$, Draft 12,894 m, and a deadweight of 85829 tons. The strait has a water depth of $100 \mathrm{~m}$ with contour variations of $\pm 2 \mathrm{~m}$. Each four cluster of mooring lines of FSO Abherka has three mooring ropes. This study analyzed the strength of mooring lines in intact and damaged conditions using DNV software Genie and DNV HydroD. This study models a hydrodynamic FSO. This study also measured the reliability of the mooring lines from 2 cases: 1 intact and one damage from the most dangerous conditions. This study used the mean Value First Order Second Moment method to find the reliability of these mooring lines. Based on the reliability calculation set by DNV according to DNV-OS E301, the mooring lines design meet the established reliability criteria.
\end{abstract}

\section{KEYWORDS:}

Floating Storage Offloading, FSO Abherka, Mooring Lines, Offshore, Reliability

\section{1 | INTRODUCTION}

Tankers are known as ships that are quite large. This occurs because of the existence of MARPOL 73/78 Part A Regulation 19, which regulates cargo space for tankers built after 6 July 1996, where the double hull and double skin must be added. It indirectly affects the size of the tanker being built ${ }^{1}$. In some cases, tankers that are more than 20 years old are converted to Floating Storage Offloading (FSO) to provide financial contributions to the tanker's owners.

Of course, tankers and floating storage offloading have different characteristics in terms of function. One of the things that must be considered in offshore floating storage is the reliability problem on mooring lines. Reliability on mooring lines is important because the FSO would be moored in the waters for a long period and face waves and water currents in local waters. Suppose the 
mooring lines at the FSO have less reliability. In that case, it can impact the safety of the FSO crew and cause economic losses for the owner because the assets do not have good mooring lines reliability. Several cases are closely related to the reliability of mooring lines, both in Indonesia and abroad, so that it becomes the concern of every owner of existing offshore assets.

PT. Pertamina (Persero), as a state-owned company (BUMN) engaged in the exploitation of oil and renewable energy, has a duty to meet domestic oil supplies for the needs of the community and industry. Today, many oil fields on land and shallow seas have been exploited so that PT. Pertamina (Persero) shifted its exploitation area to medium to deep waters. One of them is in the waters of the Madura Strait.

The Madura Strait is one of the locations for offshore exploitation, which is still a mainstay of PT Pertamina (Persero) to exploit crude oil and natural gas. With the current uncertain global oil price and increasing oil consumption with the development of the human population, it makes the operation of a fixed platform less economical than operating a floating platform that can move from one location to another.

One type of floating platform in Indonesia is floating storage and offloading (FSO). The FSO has a function to store offshore oil and gas exploitation results before being transferred by tanker to be brought ashore. PT. Pertamina (Persero) has considered choosing this FSO. This is because the FSO can move from one place to another (mobile platform) where the area cannot be exploited one day. After all, the oil and gas resources have run out. The FSO can move to a location that still has oil and gas fields. . Therefore, a floating platform has a very important role in developing deep or medium water oil fields and is the preferred alternative to a fixed platform. FSO (floating storage and offloading) is a floating platform that is widely used in operational conditions like this. The reasons for choosing an FSO as a facility in the oil and gas exploitation process, namely:

1. Can operate at depths $(100-1500) \mathrm{m}^{[2]}$.

2. Has the largest oil storage capacity $\sqrt{3}$.

3. Has the simplest and most reliable body shape in terms of structural strength at sea ${ }^{3}$.

One of the FSOs is owned by PT. Pertamina (Persero) is FSO Abherka. As mentioned earlier, FSO Abherka is an FSO operated by PT. Pertamina (Persero) at a site off the coast of the Madura Strait. This FSO is a conversion from MT Geudongdong tankers, which was held in South Korea in 2011.

The primary purpose of the mooring system is to provide seakeeping and maintain floating structure on position within a specific tolerance, typically based on offset limit. The offset limit can be varying for the various system depends on riser configuration, well position, the existence of another facility in the vicinity of the structure, etc. To provide desirable vessel offset, one can adjust the pretension on the mooring system. Hence, the determination of pretension value has a vital role in the operation of the mooring system. In recent years, the requirements for the mooring and station-keeping systems of mobile and permanent units have become more complex. The exploration is moving into new frontiers (deep water). Water depth is recognized as one of the critical parameters in the mooring system design. It would affect mooring line length, material, and configuration ${ }^{4}$.

A movement in the FSO during operation (storage and offloading) is caused by environmental loads (currents, waves, and wind). A mooring system is needed to keep the FSO in place, which is useful for tied the FSO. The motion of the FSO causes a working force (tension force, restoring force and damping) on the mooring system. The force that occurs in the mooring system depends on the characteristics of the FSO motion and vice versa. This is a reason to analyze the operability and safety of the system can be maintained ${ }^{[5]}$.

This paper conduct strength analysis on the mooring lines of a Floating Storage and Offloading (FSO) Abherka with spread mooring system. The analysis emphasizes the influence of pretension lines and environmental loads at FSO located. The result of the strength analysis of mooring lines can be used for the reliability analysis of the FSO Abherka. The result from these studies can be used as a reference for designing reliability analysis of mooring lines with a spread mooring system.

\section{2 | PREVIOUS RESEARCHES}

There are a number of previous studies related to reliability analysis on various types of mooring lines, such as FPO ${ }^{6}$, fish cages ${ }^{[7] 9]}$, vessels [10]11], deep water structures ${ }^{[12] 13}$, and semi-submersible system ${ }^{[14]}$. 
TABLE 1 Data on FSO Abherka owned by PT. Pertamina (Persero).

\begin{tabular}{lr}
\hline Characteristics & Value \\
\hline Length Overall (LOA) & $242.90 \mathrm{~m}$ \\
Length Perpendicular (LPP) & $232.00 \mathrm{~m}$ \\
Breadth (Moulded) & $41.60 \mathrm{~m}$ \\
Depth (Moulded) & $19.70 \mathrm{~m}$ \\
Draft (Existing) & $12.894 \mathrm{~m}$ \\
Dead Weight & $85,829 \mathrm{LT}$ \\
\hline Note: tsp: tea-spoon
\end{tabular}

Montes-Iturrizaga et al. ${ }^{[6]}$ analyzed the reliability of moorings under uncertainty condition of sea states using a nested model. This study was conducted on FPSOs at different water depths in Campeche Bayalso. The model the maximum dynamic line tensions with respect to conditional on the uncertain environmental variables describing extreme sea states. The model was applied to calibration of partial safety factors for the ultimate limit state.

Another study by Hou et al. ${ }^{[7 \mid}$ Furthermore, conducted time-dependent analyzing on mooring lines that are using single-cage and multi-cage systems. The study modeled the probability of corrosion depth and density on various peak period of sea states. The model estimates the tension force of mooring system for both systems and reliability level in terms of the uncertain metocean variables. Their analysis suggests that the reliability level decreases significantly with the increasing corrosion depth. Furthermore, it also suggest that the correlation of corrosion model for mooring chains has a remarkable impact on the failure probability of mooring system.

Stanisic et al. ${ }^{[1]]}$ models a reliability analysis of mooring lines on floating liquefied natural gas (FLNG) vessels. It evaluates the failure probability of mooring chain and pile. In order to achieve the same reliability for the mooring system accordance with ISO (or API), Factors of Safety (FoS) for use with 100 year environmental conditions were derived to achieve the same target probability of failure of 10-4/annum. The study shows that a mooring lines have different reliability levels on various conditions of sea states.

The study by Du et al. ${ }^{[12]}$ models a reliability analysis of mooring lines on deep-water mooring lines by considering the failure modes of floater offset excess, mooring line breakage, and fatigue. Thus, this study also conduct a quantitative relation analysis between mooring line breaking strength and cumulative fatigue damage. The study used a yer return period of data of maximum floater offset and mooring line tension on the wave condition. Another study [7] [9],16] also considered fatigue damage and its distribution. Hou et al. ${ }^{[15]}$ employed the generalized probability density evolution method (GPDEM) for modeling fatigue damage distribution problem.

\section{3 | MATERIAL AND METHOD}

In this section, the method is described from the early stage until the research was completed. We describes the stages using a flowchart. The research methods are described in Figure 1

In this study, the first step was identifying problems with data tracking. This literature research was conducted to obtain data on FSOs, and reliability analysis methods and to find out what research has been done on the dynamic behavior of FSOs. FSO data collection, FSO Abherka mooring system data from PT. Pertamina (Persero), journals, and literature at ITS. Then, the FSO was modeled with the help of DNV Genie software. The modeling in question is the FSO hull and meshing process. We modeled the FSO according to the technical data provided by PT. Pertamina is shown in Table 1 17.

After knowing the data from the FSO Abherka, the next step is to create a model from the FSO Abherka. In the modeling process, we used the DNV Genie 64 version 6.4.08 software. In this process, there is a mesh sensitivity process. This mesh sensitivity is useful for entering environmental parameters, which were later examined, and the model's reliability can be calculated. Meshing is carried out starting from the $5 \mathrm{~m}$ mesh roughness to the most detailed $1.5 \mathrm{~m}$ mesh roughness due to the limitations of processing applications in reading the maximum number of elements only up to 15,000 elements. With the computer specifications presented in Table 2 we got the number of elements in the mesh sensitivity process. They are presented in Table 3 . And Figure 2 shows how DNV Genie makes an FSO Abherka model. 


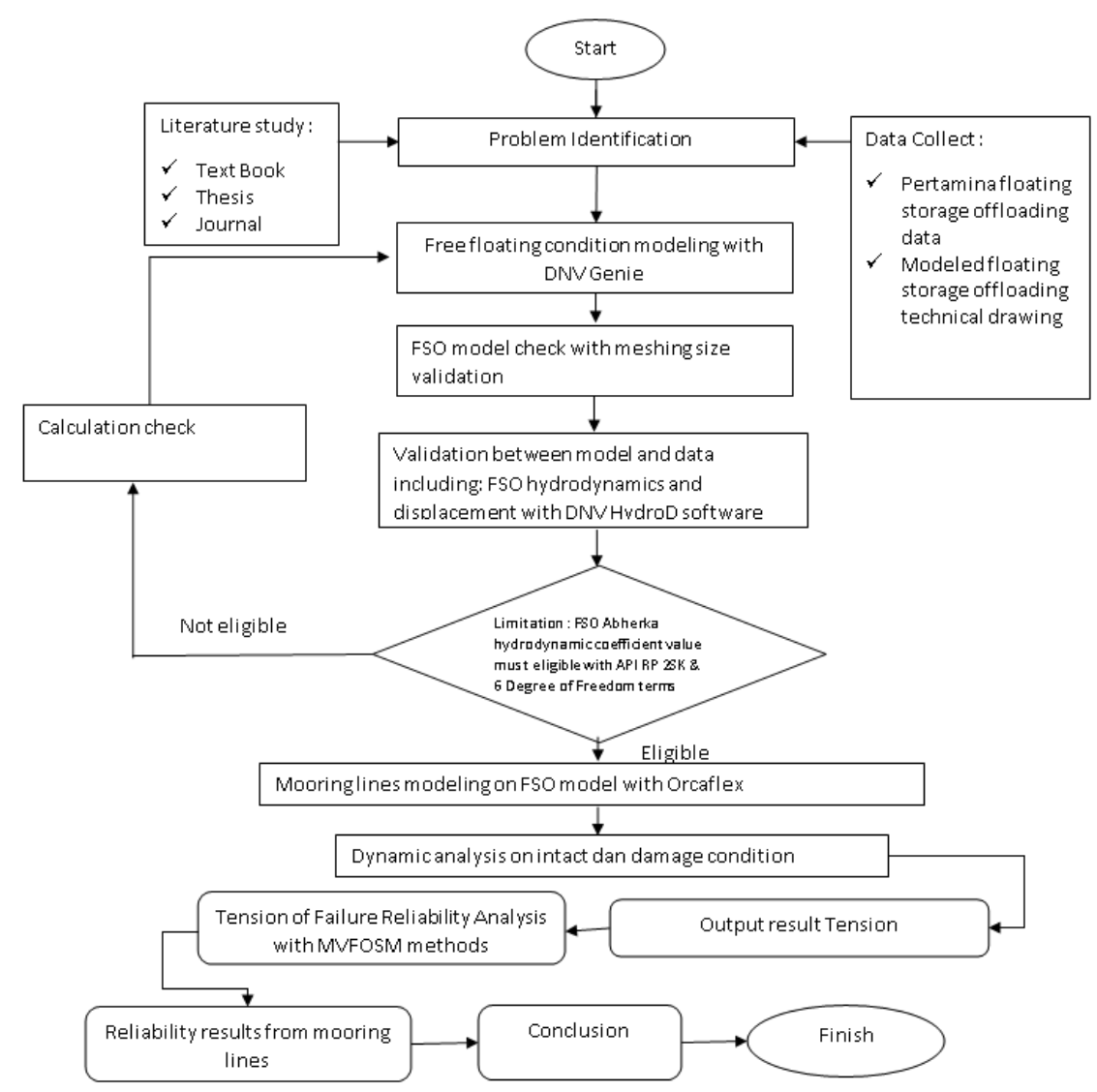

FIGURE 1 Flowchart of research methods.

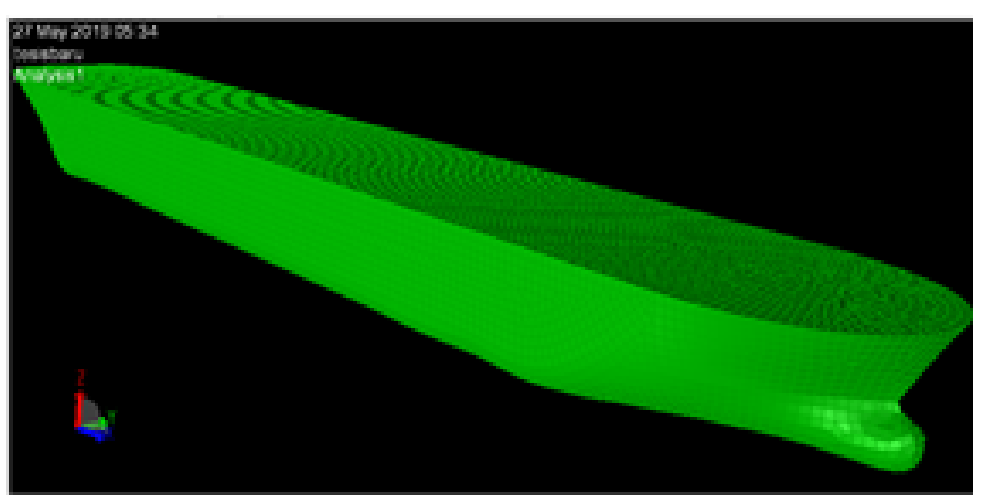

FIGURE 2 Modeling of the FSO Abherka.

From the iteration of the mesh sensitivity above, we used a mesh roughness of $2 \mathrm{~m}$. This is because, at the $2 \mathrm{~m}$ point, the mesh sensitivity has begun to converge with the other points. After modeling the FSO Abherka, we began to enter the hydrodynamic data of the FSO Abherka with the help of the DNV HydroD software. In this software, the study looked for RAO load, Quadratic Time Function (QTF) function, added mass, damping, stiffness functions, and RAO displacement from FSO Abherka. The hydrodynamic characteristics of the FSO Abherka were checked from angle 00 to angle 3450 with angles multiples of 150 and with periods from 1 second to 30 seconds. In the hydrodynamic data entry process, the FSO Abherka would be checked under 
TABLE 2 Modeling computational specifications.

\begin{tabular}{ll}
\hline Specification & Description \\
\hline Computer Name & Asus X450JN \\
RAM & $8 \mathrm{~GB}$ \\
ROM/Hardisk & $1 \mathrm{~TB}$ \\
Processor Intel & Core i7 \\
Graphics Card & Nvidia GeForce 840M \\
Built & 2014 \\
\hline
\end{tabular}

TABLE 3 Mesh Sensitivity Model FSO Abherka.

\begin{tabular}{cr}
$\begin{array}{c}\text { Mesh Width } \\
(\mathbf{m})\end{array}$ & Element \\
\hline 1.5 & 13370 \\
2.0 & 7652 \\
3.0 & 3481 \\
4.0 & 2019 \\
5.0 & 1339 \\
\hline
\end{tabular}

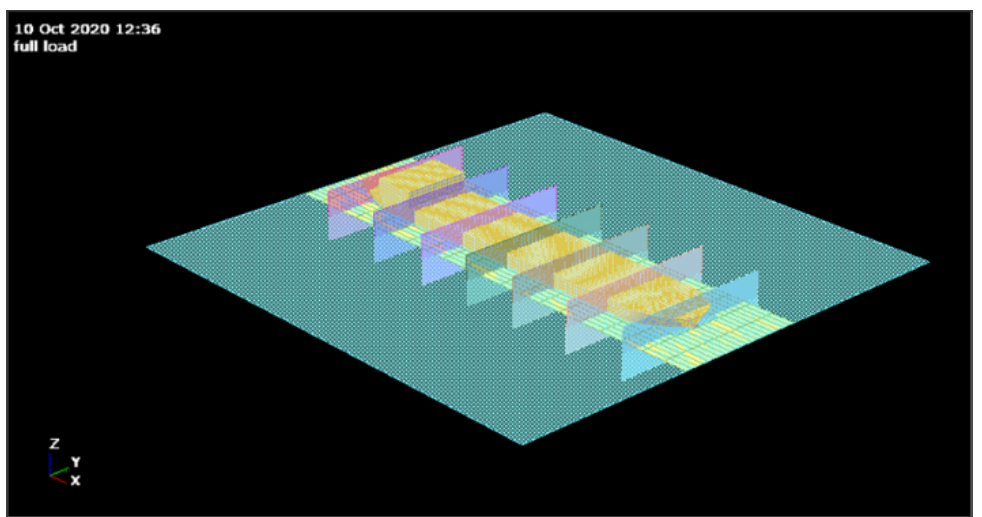

FIGURE 3 Hydrodynamic data entry of the FSO Abherka.

TABLE 4 Results of the offset analysis at the pretension of the sample given offset (Wind Full Load Damage) and angle $165^{\circ}$ (Line 5 Broken).

\begin{tabular}{cccc}
\hline $\begin{array}{c}\text { Pretension } \\
(\mathbf{k N})\end{array}$ & $X(\mathbf{m})$ & $Y(\mathbf{m})$ & $\begin{array}{c}\text { Absolute } \\
(\mathbf{m})\end{array}$ \\
\hline 850 & -26.992 & 9.462 & 28.60 \\
900 & -25.494 & 8.984 & 27.03 \\
925 & -24.781 & 8.758 & 26.28 \\
950 & -24.123 & 8.565 & 25.60 \\
961 & -23.854 & 8.480 & 25.32 \\
975 & -23.510 & 8.378 & 24.96 \\
1000 & -22.907 & 8.227 & 24.34 \\
1050 & -21.810 & 7.957 & 23.22 \\
1100 & -20.233 & 7.665 & 21.64 \\
\hline
\end{tabular}

two load conditions: the FSO in the 50\% ballast condition and the FSO in the full load condition. From several hydrodynamic data entries, POSTRESP would be obtained, which contains the hydrodynamic characteristics of the FSO Abherka. The hydrodynamic characteristics of the FSO Abherka would be used for the mooring lines modeling stage. Figure 3 shows the DNV HydroD software interface when the hydrodynamic data was entered into the FSO Abherka.

After the hydrodynamic data was entered, the modeling of the mooring lines from the FSO Abherka was started using the Orcaflex application. In this modeling process, we also tested the pretension of the mooring line with a variety of existing quantities. The configuration of the FSO is to use a spread mooring line system, adapting to conditions in the field. After modeling mooring lines, we would analyze these mooring lines by simulating the strength at an angle of $00-3450$ with a multiple of 150 for intact conditions. In this modeling process, a pretension was performed. Pretension is a process of arrangement on a mooring line to achieve a specified tension. The software would process the length of the mooring lines that anchor the marine building according to the stiffness of the mooring lines entered. In this analysis, we varied the pretension on mooring lines with variations of $850 \mathrm{kN}, 900 \mathrm{kN}, 925 \mathrm{kN}, 950 \mathrm{kN}, 961 \mathrm{kN}, 975 \mathrm{kN}, 1000 \mathrm{kN}, 1050 \mathrm{kN}$, and $1100 \mathrm{kN}$. From these pretension variations, we tested the maximum tension lines and offset values. In this case, we took the FSO Abherka in full load condition with the environmental load at the corner of 1650, and the rope number 5 on the FSO was cut. Then we get the offset in this case in Table 4 
TABLE 5 The results of the maximum tension lines analysis on the pretension of sample given wind governed (Full Load Damage) and angle $165^{\circ}$ Line 5 Broken.

\begin{tabular}{clllllllll}
\hline Line & $\mathbf{8 5 0 k N} 900 k N$ & $\mathbf{9 2 5 k N}$ & $\mathbf{9 5 0 k N}$ & $\mathbf{9 6 1 k N}$ & $\mathbf{9 7 5 k N}$ & $\mathbf{1 0 0 0 k N}$ & $\mathbf{1 0 5 0 k N}$ & $\mathbf{1 1 0 0 k N}$ \\
\hline 1 & 3162.363288 .39 & 3347.85 & 3408.41 & 3426.92 & 3456.15 & 3512.07 & 3605.01 & 3690.9 \\
2 & 4224.344292 .47 & 4324.59 & 4353.97 & 4369.07 & 4384.33 & 4411.24 & 4465.73 & 4523.42 \\
3 & 5688.545632 .98 & 5610.42 & 5589.88 & 5584.26 & 5578.03 & 5561.85 & 5544.83 & 5538.1 \\
4 & 8278.72 & 8197 & 8158.93 & 8126.86 & 8122.86 & 8109.44 & 8085.67 & 8056.99 & 8041.53 \\
5 & LN & LN & LN & LN & LN & LN & LN & LN & LN \\
6 & 4514.774706 .2 & 4799.26 & 4887.22 & 4916.37 & 4964.38 & 5047.22 & 5201.23 & 5344.57 \\
7 & 953.6 & 993.44 & 1013.3 & 1034.26 & 1043.15 & 1055.29 & 1076.7 & 1117.03 & 1161.18 \\
8 & 904.53 & 939.23 & 958.63 & 977.24 & 985.31 & 995.45 & 1014.68 & 1053.31 & 1093.74 \\
9 & 853.86 & 886.32 & 902.9 & 918.61 & 926.14 & 936.35 & 954.45 & 990.33 & 1028.19 \\
10 & 802.71 & 830.64 & 844.98 & 860.26 & 867.52 & 877.38 & 894.76 & 930.97 & 969.89 \\
11 & 830.58 & 860.83 & 878.11 & 894.67 & 901.83 & 911.55 & 929.97 & 969.1 & 1008.57 \\
12 & 858.19 & 890.98 & 907.86 & 925.92 & 93.67 & 944.72 & 964.7 & 1005.26 & 1046.64 \\
Max & 8278.728197 & 8158.93 & 8126.86 & 8122.86 & 8109.44 & 8085.67 & 8056.99 & 8041.53 \\
\hline
\end{tabular}

TABLE 6 The value of the safety factor at the tested pretension.

\begin{tabular}{lcc}
\hline Safety Factor $=$ Design MBL/Max Tension & Accept \\
\hline Pretension $850 \mathrm{kN}$ & 1.3221 & Accept \\
Pretension $900 \mathrm{kN}$ & 1.3352 & Accept \\
Pretension $925 \mathrm{kN}$ & 1.3415 & Accept \\
Pretension $950 \mathrm{kN}$ & 1.3468 & Accept \\
Pretension $961 \mathrm{kN}$ & 1.3474 & Accept \\
Pretension $975 \mathrm{kN}$ & 1.3497 & Accept \\
Pretension $1000 \mathrm{kN}$ & 1.3536 & Accept \\
Pretension $1050 \mathrm{kN}$ & 1.3584 & Accept \\
Pretension $1100 \mathrm{kN}$ & 1.3611 & Accept \\
\hline
\end{tabular}

Apart from offsets, one is obtained from the running pretension lines, namely the maximum tension lines for each pretension. we could see the maximum tension lines in one case, which took as a reference. From these two data, we took the optimal rope pretension in my case. The maximum tension lines obtained by we from running pretension are shown in Table 5 . After the maximum tension lines are obtained, we looked for the safety factor to see whether the safety factor in the pretension that we tested meets the regulations of API RP $2 \mathrm{SK}^{[18]}$. From the design, it is known that the Minimum Breaking Load (MBL) value on the mooring rope is $10945 \mathrm{KN}$. Then the explanation of the safety factors on the pretension obtained are in Table 6 Then we get the relationship between pretension and maximum safety factor and FSO Abherka offset as shown in Figure 4

From Figure 4 we could conclude that the mooring system with smaller pretension has lower dynamic line tension. However, the smaller pretension leads to a larger vessel offset and smaller mooring stiffness. This would increase the tension range and standard deviation (STD) that lead to higher strength damage (shorter strength life) ${ }^{4}$. Based on pretension tested, we took the $961 \mathrm{kN}$ pretension for load analysis testing on the FSO Abherka mooring lines. After knowing the pretension used, we began modeling the FSO Abherka and mooring lines. The mooring lines modeling of the FSO Abherka used the Orcaflex version 11.0 software, and the hydrodynamic data was taken from POSTRESP, which DNV HydroD previously searched. The visualization of the mooring lines modeling is presented in Figure 5 and the anchor location coordinates of the FSO Abherka are presented in Table 7 below.

Based on existing data, the we began to analyze the strength of the mooring lines with a simulation. This simulation is carried out by modeling the FSO and mooring lines moored in Madura waters with a depth of 100 meters and a contour variation of 2 meters. For simulations on mooring lines are carried out with the following conditions:

1. Simulations are carried out in two conditions, namely at full load conditions and 50

2. The simulation is carried out in a state of Omni-directional environmental loads. Omnidirectional is a condition in which wind, current, and waves occur with the direction coming at the same angle. Marine structures would be very vulnerable (conservative) to this omnidirectional condition. The simulation is tested from angle 00 with multiples of 150 to angle 3450 . 


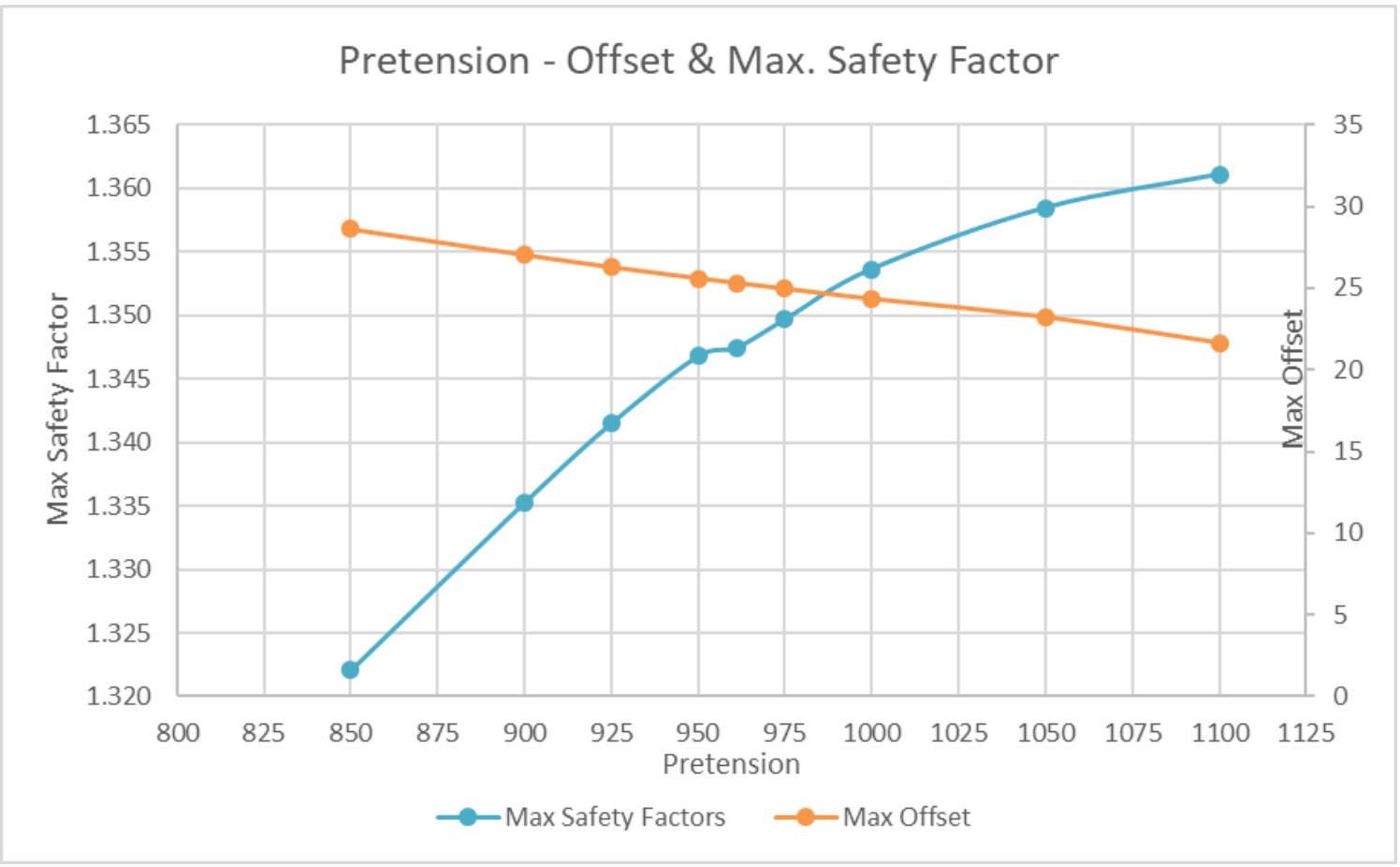

FIGURE 4 Relationship between pretension and maximum safety factor and FSO Abherka offset.

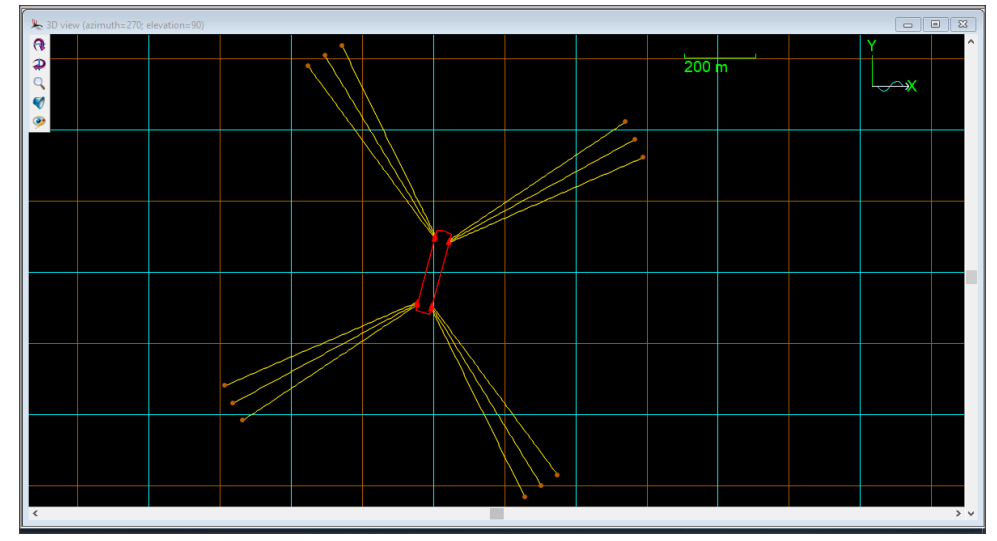

FIGURE 5 Modeling of the FSO Abherka mooring lines with Orcaflex.

3. The simulation is carried out first in an entire FSO state. Then, we take four worst cases ( 2 full loads and $250 \%$ ballast) in two angles to be analyzed in a state of damage with each corner with the worst-case analyzed in 2 mooring lines in a cluster with a maximum line tension.

4. The simulation is carried out with three conditions of wind, current, and wave parameters given by PT. Pertamina (Persero) as the owner of the FSO Abherka. The environmental loads conditions from Madura waters for this analysis are divided in three conditions. First is wave governed. This case have non squall wind speed (Ws) $12.57 \mathrm{~m} / \mathrm{s}$. Then wave sea height (Hs) $3.97 \mathrm{~m}$ with wave period (Tp) 6.6 second. And current speed (V) $2.07 \mathrm{~m} / \mathrm{s}$. Second is wind governed. This case have non squall wind speed (Ws) $14.86 \mathrm{~m} / \mathrm{s}$. Then wave sea height (Hs) $3.97 \mathrm{~m}$ with wave period (Tp) 6.6 second. And current speed (V) $2.07 \mathrm{~m} / \mathrm{s}$. And third is current governed. This case have non squall wind speed (Ws) $12.37 \mathrm{~m} / \mathrm{s}$. Then wave sea height (Hs) $3.39 \mathrm{~m}$ with wave period (Tp) 6.6 second. And current speed (V) $2.38 \mathrm{~m} / \mathrm{s}$. 
TABLE 7 Location coordinates of the anchor location of the FSO Abherka .

\begin{tabular}{lrr}
\hline Anchor & Easting & Northing \\
\hline FSO & 0 & 0 \\
Anchor 1 & 539.00 & 422.00 \\
Anchor 2 & 567.00 & 374.00 \\
Anchor 3 & 590.00 & 323.00 \\
Anchor 4 & 349.00 & -570.00 \\
Anchor 5 & 304.00 & -601.00 \\
Anchor 6 & 257.00 & -632.00 \\
Anchor 7 & -536.00 & -417.00 \\
Anchor 8 & -564.00 & -369.00 \\
Anchor 9 & -587.00 & -319.00 \\
Anchor 10 & -352.00 & 579.00 \\
Anchor 11 & -305.00 & 609.00 \\
Anchor 12 & -257.00 & 636.00 \\
\hline
\end{tabular}

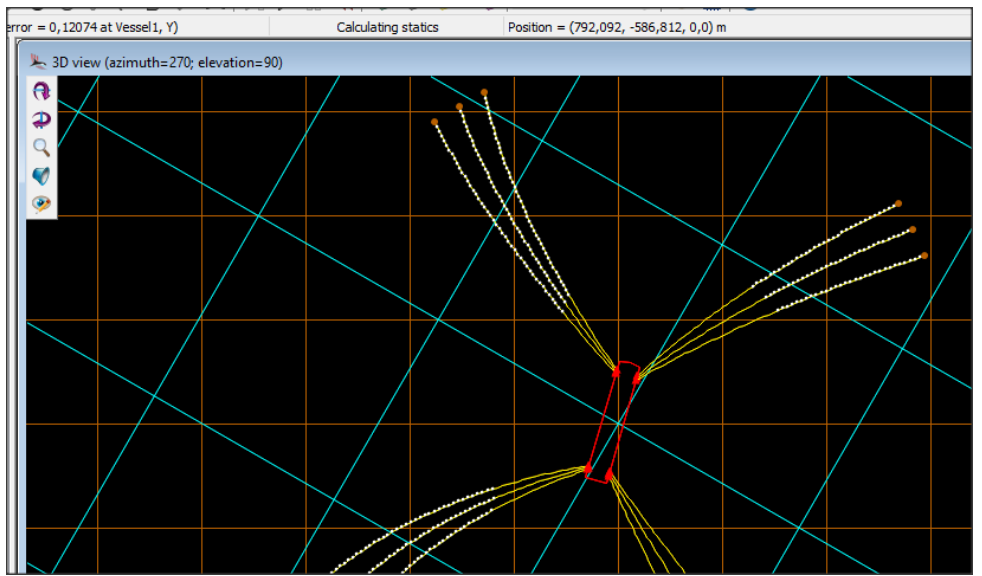

FIGURE 6 Simulation of static running on Orcaflex.

The first step in the running is to do static running. Static running is a simulation that calculates the hydrodynamic mooring lines in a static state. This is required before dynamic running is done. This is shown in Figure 6 After doing static running, the next step is to do dynamic running. Dynamic running is a simulation that calculates the $\mathrm{X}$ and $\mathrm{Y}$ values for the offset of the FSO and the maximum tension load of each mooring line tied to the FSO. This is shown in Figure 7

From the three environmental variations mentioned earlier, this simulation produces the following maximum line tension data as shown in Table 8 The result is the analysis of the maximum line tension in each case in the intact condition

From Table 8 , the we choose the four worst cases ( 2 full load and $250 \%$ ballast) for two angles. The simulation result is with the maximum line tension value in the highest intact state to be analyzed into the damage case. From the simulation above, the ones with the highest maximum line tension are at the angles of 1650 and 3450, both in ballast and full load states. At the angle that we has determined, two mooring ropes would be broken on the cluster, which gives the highest maximum tension line value to determine the strength of the mooring lines in worse conditions. To describe the analysis in a state of damage, it is presented in Table 9

After the analysis is carried out, we obtained the following analysis for the case of damage condition, as shown in Table 9 For maximum line tension analysis, according to the minimum allowance safety factor criteria of API RP 2SK, namely 1.67 for intact condition (ULS) and 1.25 for damage condition (ALS), FSO Abherka has reliable and safe mooring lines because it still meets the criteria of API RP. 2SK. Apart from the maximum line tension, we also analyzed the offset of this FSO. As in the maximum line tension analysis, the offset analysis from the FSO is carried out in two conditions, namely intact and damage. The results of the offset analysis of the FSO Abherka mooring lines are as shown in Table 11 


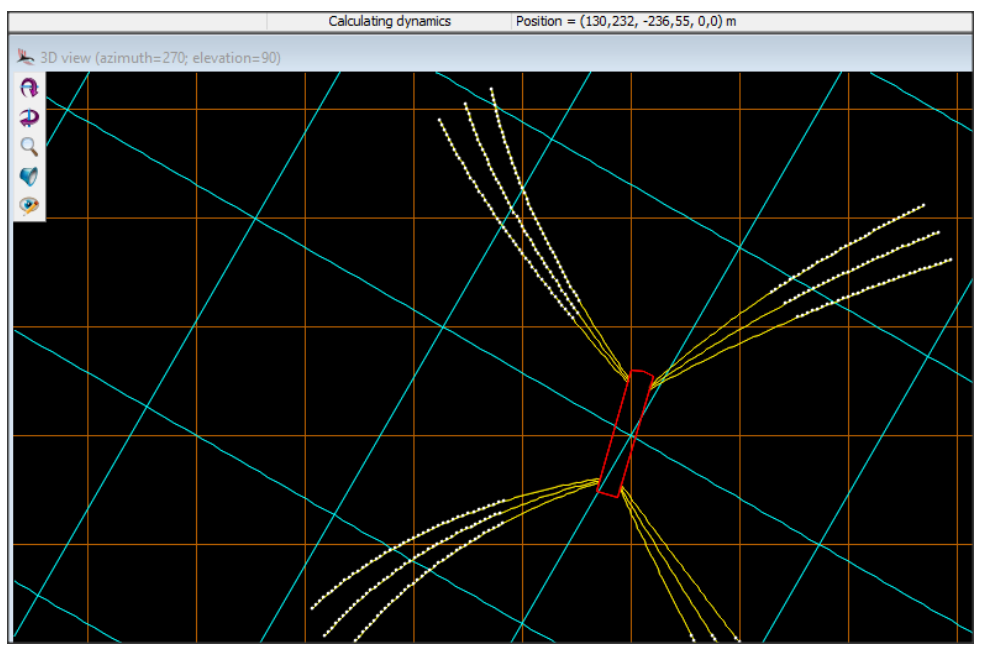

FIGURE 7 Simulation of dynamic running on Orcaflex.

TABLE 8 Results of the analysis of the maximum line tension in each case in the intact condition.

\begin{tabular}{|c|c|c|c|c|c|c|c|c|c|c|c|c|}
\hline \multirow{2}{*}{$\begin{array}{c}\text { Max } \\
\text { Tension }\end{array}$} & \multicolumn{4}{|c|}{ Wave } & \multicolumn{4}{|c|}{ Wind } & \multicolumn{4}{|c|}{ Current } \\
\hline & GB & SF & GFL & SF & GB & SF & GFL & SF & GB & SF & GFL & SF \\
\hline 0 & 3224.82 & 3.39 & 5453.16 & 2.01 & 3274.14 & 3.34 & 5487.61 & 1.99 & 3164.84 & 3.46 & 5335.29 & 2.05 \\
\hline 15 & 3068.19 & 3.57 & 3878.4 & 2.82 & 3115.7 & 3.51 & 3904.52 & 2.8 & 3043.97 & 3.6 & 4083.57 & 2.68 \\
\hline 30 & 2763.22 & 3.96 & 3101.2 & 3.53 & 2799.85 & 3.91 & 3123.06 & 3.5 & 2782.28 & 3.93 & 3341.96 & 3.28 \\
\hline 45 & 2201.61 & 4.97 & 2420.54 & 4.52 & 2228.75 & 4.91 & 2436.3 & 4.49 & 2301.79 & 4.75 & 2676.26 & 4.09 \\
\hline 60 & 1679.25 & 6.52 & 1709.32 & 6.4 & 1693.48 & 6.46 & 1718 & 6.37 & 1799.5 & 6.08 & 1915.33 & 5.71 \\
\hline 75 & 1358.72 & 8.06 & 1302.9 & 8.4 & 1364.36 & 8.02 & 1307.23 & 8.37 & 1472.73 & 7.43 & 1441.85 & 7.59 \\
\hline 90 & 1685.94 & 6.49 & 1716.34 & 6.38 & 1699.85 & 6.44 & 1725.14 & 6.34 & 1806.92 & 6.06 & 1923.6 & 5.69 \\
\hline 105 & 2210.83 & 4.95 & 2432.83 & 4.5 & 2238.88 & 4.89 & 2448.53 & 4.47 & 2312.4 & 4.73 & 2689.86 & 4.07 \\
\hline 120 & 2776.32 & 3.94 & 3117.71 & 3.51 & 2812.91 & 3.89 & 3139.13 & 3.49 & 2795.79 & 3.91 & 3359.47 & 3.26 \\
\hline 135 & 3083.76 & 3.55 & 3898.62 & 2.81 & 3131.59 & 3.5 & 3924.99 & 2.79 & 3058.44 & 3.58 & 4104.23 & 2.67 \\
\hline 150 & 3240.36 & 3.38 & 5482.65 & 2 & 3289.94 & 3.33 & 5517.12 & 1.98 & 3179.69 & 3.44 & 5363.72 & 2.04 \\
\hline 165 & 3549.41 & 3.08 & 5711.06 & 1.92 & 3608.97 & 3.03 & 5749.46 & 1.9 & 3454.96 & 3.17 & 5441.59 & 2.01 \\
\hline 180 & 3249.21 & 3.37 & 5418.66 & 2.02 & 3300.42 & 3.32 & 5453.65 & 2.01 & 3197.66 & 3.42 & 5372.11 & 2.04 \\
\hline 195 & 3141.64 & 3.48 & 3819.23 & 2.87 & 3187.17 & 3.43 & 3843.64 & 2.85 & 3101.25 & 3.53 & 4072.48 & 2.69 \\
\hline 210 & 2833.37 & 3.86 & 3124.6 & 3.5 & 2873.34 & 3.81 & 3145.21 & 3.48 & 2848.56 & 3.84 & 3375.31 & 3.24 \\
\hline 225 & 2244.79 & 4.88 & 2449.28 & 4.47 & 2272.56 & 4.82 & 2465.37 & 4.44 & 2340.74 & 4.68 & 2712.33 & 4.04 \\
\hline 240 & 1689.96 & 6.48 & 1726.12 & 6.34 & 1703.98 & 6.42 & 1734.74 & 6.31 & 1807.62 & 6.05 & 1936.81 & 5.65 \\
\hline 255 & 1345.88 & 8.13 & 1315.85 & 8.32 & 1351.26 & 8.1 & 1320.23 & 8.29 & 1459.43 & 7.5 & 1451.38 & 7.54 \\
\hline 270 & 1675.85 & 6.53 & 1710.83 & 6.4 & 1689.68 & 6.48 & 1719.36 & 6.37 & 1792.37 & 6.11 & 1919.02 & 5.7 \\
\hline 285 & 2221.18 & 4.93 & 2421.66 & 4.52 & 2248.49 & 4.87 & 2437.57 & 4.49 & 2315.19 & 4.73 & 2679.63 & 4.08 \\
\hline 300 & 2802.13 & 3.91 & 3087.18 & 3.55 & 2839.74 & 3.85 & 3107.51 & 3.52 & 2814.46 & 3.89 & 3332.84 & 3.28 \\
\hline 315 & 3105.94 & 3.52 & 3773.71 & 2.9 & 3150.51 & 3.47 & 3798.58 & 2.88 & 3065.79 & 3.57 & 4021.81 & 2.72 \\
\hline 330 & 3213.87 & 3.41 & 5354.14 & 2.04 & 3263.96 & 3.35 & 5389.01 & 2.03 & 3162.44 & 3.46 & 5308.23 & 2.06 \\
\hline 345 & 3533.5 & 3.1 & 5680.18 & 1.93 & 3592.47 & 3.05 & 5718.89 & 1.91 & 3438.78 & 3.18 & 5407.2 & 2.02 \\
\hline 360 & 3224.82 & 3.39 & 5453.16 & 2.01 & 3274.14 & 3.34 & 5487.61 & 1.99 & 3164.84 & 3.46 & 5335.29 & 2.05 \\
\hline
\end{tabular}

GB: Governed Balance; SF: Safety Factors; GFL: Governed Full Load

With a depth of 100 meters deep in Madura waters, the offset from the FSO Abherka is less than $30 \%$ of the depth of Madura waters, which is the project specification set by PT. Pertamina.

\section{4 | RESULTS AND DISCUSSION}

By analyzing the strength of the mooring lines obtained, we searched for the reliability of the FSO Abherka mooring lines. The method used to find the reliability of the FSO Abherka mooring lines was the Mean Value First Order Second Moment (MVFOSM) method 19. This is based on the relationship between the value of mooring line tension and reliability. In the MVFOSM method, we looked for $\mu_{F}$. From the iterations that have been carried out, we got the $\mu_{S}$, where the $\mu \mathrm{S}$ in this author's problem is the average strength of the mooring rope that we studied. Then $\mu_{L}$ is the average of the maximum effective tension 
TABLE 9 Arrangement of damage condition analysis on mooring lines FSO Abherka.

\begin{tabular}{lccc}
\hline Angle & LWMLT & Cluster & LTC \\
\hline 165 & 4 & 2 & 5 \\
& & & 6 \\
345 & 9 & 3 & 7 \\
& & & 8 \\
\hline
\end{tabular}

LWMLT: Line with maximum tension; LTC: Line to be cut

TABLE 10 Results of the maximum line tension analysis for each case in a damaged condition.

\begin{tabular}{|c|c|c|c|c|c|c|c|c|c|c|c|c|}
\hline \multirow{2}{*}{$\begin{array}{c}\text { Max } \\
\text { Tension }\end{array}$} & \multicolumn{4}{|c|}{ Wave } & \multicolumn{4}{|c|}{ Wind } & \multicolumn{4}{|c|}{ Current } \\
\hline & GB & SF & GFL & SF & GB & SF & GFL & SF & GB & SF & GFL & SF \\
\hline $\begin{array}{c}165 \text { Line } 5 \\
\text { Broken }\end{array}$ & 5052.07 & 2.17 & 8121.15 & 1.35 & 5148.06 & 2.13 & 8122.86 & 1.35 & 4937.03 & 2.22 & 7735.55 & 1.41 \\
\hline $\begin{array}{c}\text { 165Line } 6 \\
\text { Broken }\end{array}$ & 4626.13 & 2.37 & 7161.52 & 1.53 & 4707.23 & 2.33 & 7207.36 & 1.52 & 4536.83 & 2.41 & 6861.17 & 1.6 \\
\hline $\begin{array}{c}\text { 345Line } 7 \\
\text { Broken }\end{array}$ & 4620.72 & 2.37 & 7153.23 & 1.53 & 4702.23 & 2.33 & 7198.68 & 1.52 & 4532.46 & 2.41 & 6853.7 & 1.6 \\
\hline $\begin{array}{c}345 \text { Line } 8 \\
\text { Broken }\end{array}$ & 5019.21 & 2.18 & 8059.47 & 1.36 & 5113.89 & 2.14 & 8110.87 & 1.35 & 4904.54 & 2.23 & 7680.59 & 1.43 \\
\hline $\begin{array}{c}165 \text { Line } 5 \\
\text { Broken }\end{array}$ & 5052.07 & 2.17 & 8121.15 & 1.35 & 5148.06 & 2.13 & 8122.86 & 1.35 & 4937.03 & 2.22 & 7735.55 & 1.41 \\
\hline
\end{tabular}

GB: Governed Balance; SF: Safety Factors; GFL: Governed Full Load

of the running process carried out in the Orcaflex software in 2 cases that we took. Then obtained $\mu \mathrm{F}$ being the excess of $\mu$ s and $\mu_{L}$ as shown in Table 12

After knowing the $\mu_{F}$ or mean value of these two cases, then we searched for the standard deviation of $\sigma \mathrm{F}$. For $\sigma \mathrm{s}$, or the standard deviation of the strength is $10 \%$ of the Minimum Breaking Load (MBL) of the mooring rope. Then for $\sigma \mathrm{L}$ or the standard deviation of the load, it is taken from the standard deviation of the maximum difference in the maximum tension load of the two cases selected based on a standard deviation of $25 \%$, with the character of the FSO Abherka waters installed at a depth of $100 \mathrm{~m}$. From the iteration that we have done, the $\sigma \mathrm{L}$ is obtained, and we get $\sigma \mathrm{F}$ which is a function of the root of the sum of the standard deviation of the strength squared and the standard deviation of the squared load as shown in Table 13

After the $\mu_{F}$ and $\sigma \mathrm{F}$ are obtained, it can be seen that the reliability index or $\beta$ of the reliability of Abherka's FSO mooring lines, where the reliability index is obtained from the division between $\mu_{F}$ and $\sigma_{F}$. After $\beta$ is obtained, we looked for $\Phi$ or standard normal distribution. To get $\Phi$, it can be obtained by the following equation:

$$
\Phi=S i \sqrt{t+b}
$$

Where $\mathrm{x}$ is the reliability index. By knowing the quantity $\Phi$, we could find PF, the multiplication function of $\Phi$ by $\beta$. For $\beta$, $\Phi$ and PF shown in Table 14 With the reliability of having the equation $K=1$ - PF, the reliability of mooring lines in the 2 cases selected at the FSO Abherka is obtained as shown in Table 15

\section{5 | CONCLUSION}

From the discussion of this study, we conclude that in omni-directional conditions, the reliability of mooring lines in the intact condition is 0.999990055 , and the damage condition is 0.987211486 . Decrease from intact condition to damage condition by $1.3 \%$. This omnidirectional condition is when the environmental load that affects the reliability of mooring lines is in the same direction. Then FSO Abherka has reliable mooring lines because, with known existing reliability, mooring lines meet the requirements of the DNV-OS E301 rules. This is based on a regulation from DNV-OS E301, which states that the probability of failure does not exceed $1 *$ 10-5 in an intact condition, so it can be concluded that in worse conditions, the mooring lines of FSO Abherka have reliability which is still within the scope of the DNV regulations- OS E301 [20]. The intact condition itself is a 
TABLE 11 Analysis of the offsets of the FSO Abherka with various conditions.

\begin{tabular}{|c|c|c|}
\hline Offset Condition & Angle (Degree) & $\begin{array}{l}\text { Max Offset } \\
\text { (m) }\end{array}$ \\
\hline Wave Governed (Bal- & 165 & 20.64 \\
\hline last) & 345 & 21.01 \\
\hline Wave Governed (Bal- & 165 Line 5 Broken & 22.43 \\
\hline \multirow[t]{3}{*}{ last Damage) } & 165 Line 6 Broken & 21.81 \\
\hline & 345 Line 7 Broken & 22.10 \\
\hline & 345 Line 8 Broken & 22.68 \\
\hline Wave Governed (Full & 165 & 27.29 \\
\hline Load) & 345 & 27.62 \\
\hline Wave Governed (Full & 165 Line 5 Broken & 28.70 \\
\hline \multirow{3}{*}{ Load Damage) } & 165 Line 6 Broken & 28.02 \\
\hline & 345 Line 7 Broken & 28.36 \\
\hline & 345 Line 8 Broken & 29.00 \\
\hline Wind Governed (Bal- & 165 & 20.78 \\
\hline last) & 345 & 21.16 \\
\hline Wind Governed (Bal- & 165 Line 5 Broken & 22.58 \\
\hline \multirow{3}{*}{ last Damage) } & 165 Line 6 Broken & 21.95 \\
\hline & 345 Line 7 Broken & 22.26 \\
\hline & 345 Line 8 Broken & 22.83 \\
\hline Wind Governed (Full & 165 & 27.33 \\
\hline Load) & 345 & 27.66 \\
\hline Wind Governed (Full & 165 Line 5 Broken & 25.32 \\
\hline \multirow[t]{3}{*}{ Load Damage) } & 165 Line 6 Broken & 28.06 \\
\hline & 345 Line 7 Broken & 28.39 \\
\hline & 345 Line 8 Broken & 29.05 \\
\hline Governed & 165 & 19.28 \\
\hline (Ballast) & 345 & 19.65 \\
\hline Governed & 165 Line 5 Broken & 21.19 \\
\hline \multirow[t]{3}{*}{ (Ballast Damage) } & 165 Line 6 Broken & 20.58 \\
\hline & 345 Line 7 Broken & 20.87 \\
\hline & 345 Line 8 Broken & 21.43 \\
\hline Current Governed & 165 & 25.55 \\
\hline (Full Load) & 345 & 25.91 \\
\hline Current Governed & 165 Line 5 Broken & 27.13 \\
\hline \multirow{3}{*}{ (Full Load Damage) } & 165 Line 6 Broken & 26.49 \\
\hline & 345 Line 7 Broken & 26.81 \\
\hline & 345 Line 8 Broken & 27.43 \\
\hline
\end{tabular}

TABLE 12 Results of average for the two authors' samples.

\begin{tabular}{lccc}
\hline Case & $\mu_{F}(\mathbf{K N})$ & $\mu_{L}(\mathbf{K N})$ & $\mu_{F}(\mathbf{K N})$ \\
\hline $\begin{array}{l}\text { Case 1650 intact } \\
\text { wind full load }\end{array}$ & 10945 & 4517.74 & 6427.26 \\
$\begin{array}{l}\text { Case 1650 damage } \\
\text { wind full load }\end{array}$ & 10945 & 6519.61 & 4425.39 \\
\hline
\end{tabular}

TABLE 13 Results of deviation standard in the two authors' samples.

\begin{tabular}{lccc}
\hline Case & $\sigma_{F}(\mathbf{K N})$ & $\sigma_{L}(\mathbf{K N})$ & $\sigma F(\mathbf{K N})$ \\
\hline $\begin{array}{l}\text { Case 1650 intact } \\
\text { wind full load }\end{array}$ & 1094.5 & 703.95 & 1301.34 \\
$\begin{array}{l}\text { Case 1650 damage } \\
\text { wind full load }\end{array}$ & 1094.5 & 978.34 & 1468.02 \\
\hline
\end{tabular}

condition that refers to the ultimate limit state or when the marine building is in normal condition. And do not forget, in managing the reliability of mooring lines, pretension analysis on mooring lines is necessary because it would affect the offset and the maximum tension load, which affects the reliability of the mooring lines.

From this study, we would like to address two future-action recommendations for the stakeholder. First, there should be mooring lines variations to get the best type of mooring lines for the FSO owned by Pertamina (Persero). Second, the floating structure study should be increased due to the oil and gas market is fixed on the downstream and the upstream.

\section{CREDIT}

We would like to thank Mr. Jimmy, who I cannot mention his services one by one for the success of this research, PT. Pertamina (PERSERO) Shipping Co. as an agency of the first author's research that always provides convenience in providing data and parties that could not be mentioned one by one in the success of writing this research. 
TABLE 14 Results of $\beta, \phi$ and PF in two samples.

\begin{tabular}{lccc}
\hline Case & $\beta$ & $\Phi$ & $P F(\mathbf{K N})$ \\
\hline $\begin{array}{l}\text { Case 1650 intact } \\
\text { wind full load }\end{array}$ & 4.94 & $2.01 \mathrm{E}-06$ & $9.94 \mathrm{E}-06$ \\
$\begin{array}{l}\text { Case 1650 damage } \\
\text { wind full load }\end{array}$ & 3.01 & $4.24 \mathrm{E}-03$ & $1.28 \mathrm{E}-02$ \\
\hline
\end{tabular}

TABLE 15 Reliability of mooring lines in the two authors' samples.

\begin{tabular}{lc}
\hline Case & K \\
\hline $\begin{array}{l}\text { Case 1650 intact } \\
\text { wind full load }\end{array}$ & 0.999990055 \\
$\begin{array}{l}\text { Case 1650 damage } \\
\text { wind full load }\end{array}$ & 0.987211486 \\
\hline
\end{tabular}

\section{CREDIT}

Garry Raditya Putra: Software, Visualization. Daniel M. Rosyid: Methodology, Formal Analysis, Investigation, Supervision. Rudi Walujo Prastianto: Writing - Review and Editing, Formal Analysis, Investigation, Supervision.

\section{References}

1. Lewis EV. Principles of Naval Architecture Second Revision, vol. 2 of Resistance, Propulsion and Vibration. Jersey City NJ: The Society of Naval Architects \& Marine Engineers; 2001.

2. Murdjito. Handout Perancangan Konstruksi Bangunan Laut 2. 1. ed. Surabaya: ITS Press; 2005.

3. Indiyono P. Hidrodinamika Bangunan Lepas Pantai. 1. ed. Surabaya: SIC; 2004.

4. Sabana NM, Djatmiko EB, Prastianto RW. Fatigue Life of Mooring Lines on External Turret Floating LNG for Different Pretension and Water Depth; 2019, (in press).

5. Djatmiko EB. Perilaku Bangunan Apung di atas Gelombang. 1. ed. Surabaya: ITS Press; 2003.

6. Montes-Iturrizaga R, Heredia-Zavoni E, Silva-González F, Straub D. Nested reliability analysis of mooring lines for floating systems. Applied Ocean Research 2012;34:107-115. https://www.sciencedirect.com/science/article/pii/ S0141118711000812

7. Hou HM, Xu TJ, Dong GH, Zhao YP, Bi CW. Time-dependent reliability analysis of mooring lines for fish cage under corrosion effect. Aquacultural Engineering 2017;77:42-52. https://www.sciencedirect.com/science/article/pii/ S0144860916301108

8. Hou HM, Dong GH, Xu TJ, Zhao YP. System reliability evaluation of mooring system for fish cage under ultimate limit state. Ocean Engineering 2019;172:422-433. https://www.sciencedirect.com/science/article/pii/S0029801818313970

9. Hou HM, Dong GH, Xu TJ, Zhao YP, Bi CW, Gui FK. Fatigue reliability analysis of mooring system for fish cage. Applied Ocean Research 2018;71:77-89. https://www.sciencedirect.com/science/article/pii/S0141118717303310

10. Stanisic D, Efthymiou M, Kimiaei M, Zhao W. Design loads and long term distribution of mooring line response of a large weathervaning vessel in a tropical cyclone environment. Marine Structures 2018;61:361-380. https://www.sciencedirect. com/science/article/pii/S0951833917301454

11. Stanisic D, Efthymiou M, White DJ, Kimiaei M. Mooring system reliability in tropical cyclone and North Sea winter storm environments. Applied Ocean Research 2019;88:306-316. https://www.sciencedirect.com/science/article/pii/ S0141118718307302]

12. Du J, Chang A, Wang S, Sun M, Wang J, Li H. Multi-mode reliability analysis of mooring system of deep-water floating structures. Ocean Engineering 2019;192:106517. https://www.sciencedirect.com/science/article/pii/S0029801819306560

13. Li H, Guedes Soares C, Huang HZ. Reliability analysis of a floating offshore wind turbine using Bayesian Networks. Ocean Engineering 2020;217:107827. https://www.sciencedirect.com/science/article/pii/S0029801820308003 
14. Xu S, Teixeira AP, Guedes Soares C. Conditional Reliability Analysis of a Semi-Submersible Mooring Line With Random Hydrodynamic Coefficients. Journal of Offshore Mechanics and Arctic Engineering 2019 09;142(1). https://doi.org/10. 1115/1.4044653, 011606.

15. Hou HM, Dong GH, Xu TJ. Fatigue damage distribution and reliability assessment of grid mooring system for fish cage. Marine Structures 2019;67:102640. https://www.sciencedirect.com/science/article/pii/S0951833918304386

16. Thies PR, Johanning L, Harnois V, Smith HCM, Parish DN. Mooring line fatigue damage evaluation for floating marine energy converters: Field measurements and prediction. Renewable Energy 2014;63:133-144. https://www.sciencedirect. com/science/article/pii/S0960148113004667

17. Shipping P. General Arrangements of FSO Abherka. Jakarta; 2011.

18. API. Design and Analysis of Stationkeeping Systems for Floating Structures. 1. ed. Washington: American Petrolium Institute; 2015.

19. Rosyid DM. Pengantar Rekayasa Keandalan. 1. ed. Surabaya: Airlangga University; 2007.

20. DNV. Position Mooring. 3. ed. Norway: Det Norske Veritas; 2018.

How to cite this article: Putra G.R., Rosyid D.M., Prastianto R.W. (2021), Mooring Lines Reliability Analysis Case Study: Fso Abherka, IPTEK The Journal of Technology and Science, 32(1):41-53. 